\title{
Species richness of crustacean zooplankton and trophic structure of brackish lagoons in contrasting climate zones: north temperate Denmark and Mediterranean Catalonia (Spain)
}

\author{
Sandra Brucet, Dani Boix, Stéphanie Gascón, Jordi Sala, Xavier D. Quintana, Anna Badosa, \\ Martin Søndergaard, Torben L. Lauridsen and Erik Jeppesen
}

S. Brucet (sandra.brucet@gmail.com), M. Søndergaard, T. L. Lauridsen and E. Jeppesen, National Environmental Research Inst., Aarhus Univ., Vejlsøvej 25, PO Box 314, DK-8600 Silkeborg, Denmark. - D. Boix, S. Gascón, J. Sala and X. D. Quintana, Inst. of Aquatic Ecology and Dept of Environmental Sciences, Univ. of Girona, Campus de Montilivi, Facultat de Ciencies, ES-17071 Girona, Spain. - A. Badosa, Dept of Wetland Ecology, Doñana Biological Station-CSIC, Avda Maria Luisa s/n, ES-41013 Sevilla, Spain.

\begin{abstract}
We sought to identify environmental factors influencing crustacean zooplankton species richness in brackish lagoons and to elucidate whether crustacean zooplankton species richness and trophic structure of brackish lagoons differ among two regions with contrasting temperatures. We sampled 35 and 42 brackish lagoons (salinity ranging from 0.3 to $55 \%$ ) in Mediterranean Catalonia (NE Spain) and northern-temperate Denmark, respectively. No significant differences were found in total crustacean zooplankton species richness or cladoceran richness between the climatic regions. Calanoid richness was higher in Denmark than in Catalonia, while cyclopoid richness was higher in Catalonia. Salinity was the most important variable associated with zooplankton species richness in both regions, richness of total zooplankton species, cladocerans and cyclopoids being negatively related with salinity. In both regions, a shift occurred from dominance of large filter feeding cladoceran species at low salinities to copepods and small cladoceran species at higher salinities. Cladoceran richness increased with increasing total phosphorus, but was not influenced by total nitrogen or chlorophyll-a. Trophic structure in Mediterranean brackish lagoons showed a more pronounced seasonal variation than in north temperate brackish lagoons. Our results imply that the indirect effects of climate warming, such as changes in salinity and hydrology, will have a larger impact on brackish lagoon ecosystems than the increase in temperature per se.
\end{abstract}

Brackish lakes and lagoons (termed lagoons in this paper) are numerous in many parts of the world (Irvine et al. 1990, Moss 1994), but information on the factors controlling taxon richness and trophic structure in such lagoons is scarce. In freshwater lakes, species richness is influenced by several local factors, including lake morphometry, latitude, climate, productivity, water plant cover, and by biological interactions such as predation and competition (Jeppesen et al. 2000, Oertli et al. 2002, Declerck et al. 2005, Gyllström et al. 2005). Regional factors such as variation in dispersal and connectivity may also play a role (Cottenie et al. 2003). A key structuring factor for invertebrate communities in brackish lagoons is salinity, and decreased species richness has been found with increasing salinity (Jeppesen et al. 1994, Moss 1994, Cognetti and Maltagliati 2000, Schallenberg et al. 2003). The decline occurs rapidly within the salinity range $0-10 \%$ and more slowly at salinities $>10 \%$ (Williams et al. 1990). However, Grindley (1981) found a decrease in species richness from freshwater to $2 \%$ salinity and an increase from 2 to $13 \%$. Although much less studied, salinity and hydrology are considered the main environmental factors structuring the invertebrate community in Mediterranean lakes and brackish lagoons (Beklioglu et al. 2007, Boix et al. 2008). Studies in this region have demonstrated both a decrease in zooplankton species richness and changes in the species composition with increasing salinity (Boronat et al. 2001, Green et al. 2005, Boix et al. 2008).

There is also emerging evidence that trophic structure differs substantially among freshwater lakes and brackish lagoons (Irvine et al. 1990, Moss 1994, Jeppesen et al. 1994, 2007a). Temperate eutrophic and hypertrophic brackish lagoons are often dominated by small planktivorous fish, such as sticklebacks (Gasterosteus aculeatus and Pungitius pungitius), and they have more cohorts per year than in comparable freshwater lakes. These small fish are abundant in the vegetation, implying that zooplankton cannot use submerged macrophytes as a daytime refuge to the same extent as in temperate freshwater lakes dominated by larger planktivorous fish (Jeppesen et al. 1997). The result is higher fish predation on zooplankton and, in turn, a markedly lower grazing pressure from zooplankton on 
phytoplankton. Eutrophic temperate brackish lagoons are therefore often more turbid than comparable temperate freshwater lakes (Jeppesen et al. 1994, 2007a). Dominance of small and more omnivorous fish species and more frequent spawning have also been observed in freshwater lakes in the Mediterranean (Blanco et al. 2003) and the tropics (Lazzaro et al. 2003) than in temperate regions, and this has been attributed to a warmer climate (Jeppesen et al. 2007b). Also piscivory appears to be less intense than at comparable temperate localities (Blanco et al. 2003). In Mediterranean shallow freshwater lakes, the higher predation on zooplankton results in lower zooplankton:phytoplankton biomass ratios than in temperate lakes (Romo et al. 2004, Gyllström et al. 2005). In Mediterranean brackish lagoons, the size structure of zooplankton, often with dominance of small sized zooplankton (rotifers and nauplii), is indicative of high fish predation (Brucet et al. 2005, Badosa et al. 2007).

In a scenario of a future warmer climate, the salinity of brackish and also freshwater lakes and lagoons may increase due to higher evaporation mediated by a warmer and drier climate, intrusion of sea water to the lakes due to the rise in sea levels, and enhanced use of freshwater for, for instance, irrigation and industry (Williams 2001). Increased salinisation has already been observed in many freshwater, brackish and inland saline lakes and lagoons around the world, entailing decreased biodiversity and alterations in the ecosystem functioning (Aladin 1991, Moss 1994, Williams 2001, Schallenberg et al. 2003). Cross-comparison of brackish lagoons in regions differing in temperature and hydrology may help identify the effects of global warming and salinisation on species richness and trophic structure. With this aim we sampled a set of lagoons in two contrasting climatic regions: north temperate Denmark and Mediterranean Catalonia, Spain. We assessed the differences in the species richness of crustacean zooplankton and the planktonic trophic structure between brackish lagoons within these two regions, and examined the influence of some environmental variables on crustacean zooplankton species richness. We hypothesised 1) that salinity would be the main controlling factor of species richness in brackish lakes and that higher salinities would be associated with lower species richness in both regions, 2) that differences in salinity among lagoons would be more important for determining crustacean species richness than differences in temperature between regions and 3) that trophic structure would be more variable in Catalan than in Danish brackish lagoons due to higher seasonal variation in hydrology and thus water level in the Mediterranean region.

\section{Methods}

\section{Study site and sampling methodology}

The study was conducted in 35 coastal shallow brackish lagoons located throughout Catalonia (NE Spain) and 42 lagoons located throughout Denmark. Samplings were conducted in winter (February-March) and in summer (June-July, in Catalonia and August, in Denmark) to take into account the seasonal changes. All lagoons were sampled twice, except for Denmark where 15 lagoons were only sampled during winter. Information on water and lagoon characteristics for each region is summarised in Table 1.

For zooplankton, depth integrated samples were taken at a mid-lagoon station. The water (10-12 l) was mixed in a barrel and an 81 subsample was filtered through a $50 \mu \mathrm{m}$ filter to collect zooplankton which was immediately preserved in Lugol's solution. Copepods and cladocerans were identified to species level in the laboratory and their presence/absence was recorded in each sample. In order not to miss rare species, we examined the whole sample. The genera Daphnia, Simocephalus and Megafenestra were classed as large-bodied cladocerans.

Water samples were taken for analysis of total phosphorus (TP), total nitrogen (TN) and chlorophyll-a. Temperature and salinity were measured in situ. In Danish lagoons, TP and TN were determined following Koroleff (1970) and Solórzano and Sharp (1980), respectively, and in Catalan lagoons according to, respectively, Grasshoff et al. (1983) and APHA (1989). Chlorophyll-a was determined spectrophotometrically after extraction in ethanol (Danish lagoons) and methanol (Catalan lagoons) following Talling and Driver (1963).

\section{Species richness comparisons}

Species richness was measured as the total number of species of crustacean zooplankton in a lagoon. Two approaches were used to undertake comparisons between regions and sampling periods. The first was based on the species richness per visit. Two-way analyses of variance (ANOVA) were used to test the differences in total, calanoid, cyclopoid and cladoceran richness per visit between regions and seasons. These analyses were performed using SPSS 14 for Windows. The second approach involved the use of rarefaction curves, obtained by resampling from a pooled group of samples and plotting the expected number of species against an increasing number of samples, thereby

Table 1. Selected physical, chemical and biological characteristics in the Catalan and Danish lagoons in winter (February-March) and summer (June-July, in Catalonia and August, in Denmark).

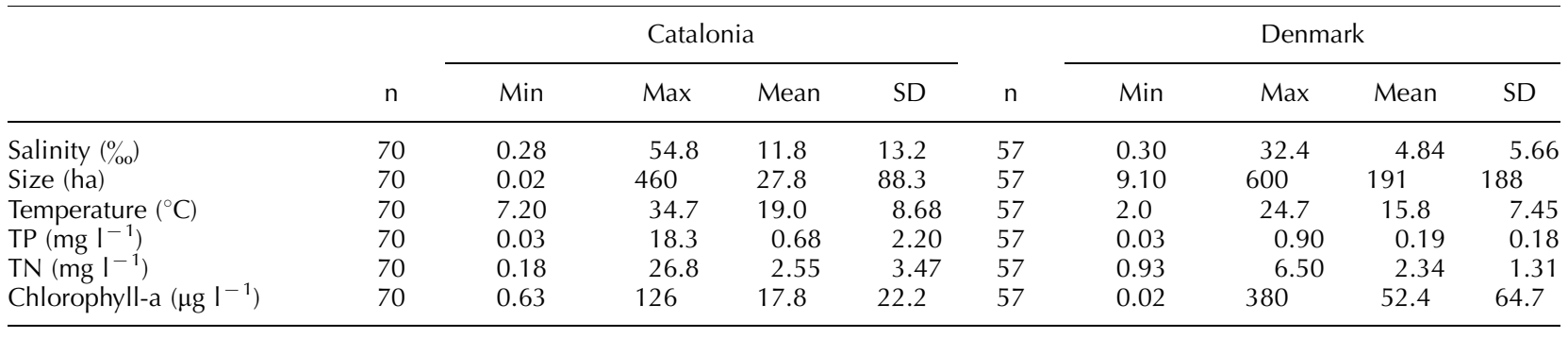


adjusting for differences in sample size. Sample-based rarefaction curves were tracked with EstimateS 7.5 software (Colwell 2005). To compare species accumulation curves among regions and seasons, samples for each region and sampling period (winter and summer) were randomised with replacement, and Mao Tau estimator of rarefied species richness $(\tau(\mathrm{h}))$ was used as it allows rigorous comparisons among sample-based rarefaction curves due to the existence of legitimate confidence intervals at all points along the curve (Colwell et al. 2004).

To obtain estimates of the richness of different zooplankton groups for each region and sampling period, the Chao2 estimator was calculated (Hortal et al. 2006). The bias-corrected formula of the Chao 2 estimator was used when Chao's estimated coefficient of variation (CV) for abundance distribution was $<0.5$; otherwise, the classic Chao2 estimator was used (Colwell 2005). The criterion used to determine if the results obtained with the rarefaction curves, rarefied species richness $(\tau(\mathrm{h}))$ and the Chao 2 estimator were significantly different among regions and seasons $(p<0.05)$ was the absence of overlap among the $95 \%$ confidence intervals (CI) (see values in Table 2) (Colwell et al. 2004).

The Sørensen similarity index (QS) was used for measuring similarity in species composition for the two regions:

$\mathrm{QS}=\frac{2 \mathrm{C}}{\mathrm{A}+\mathrm{B}}$

where $\mathrm{A}$ and $\mathrm{B}$ are the species numbers in Catalonia and Denmark and $C$ is the number of shared species by two regions.

\section{Environmental variables responses on species richness}

To identify which environmental variables influenced crustacean zooplankton species richness, we used generalized linear models (GLM; McCullagh and Nelder 1989). Two different datasets, one for each sampling period (winter and summer), were used in the GLM analyses to avoid interdependence among the datasets. For each sampling period, four GLM analyses were run for total, cladoceran, calanoid and cyclopoid species richness, respectively. In each GLM, six variables were included: lagoon size, temperature, salinity, total phosphorus, total nitrogen and chlorophyll-a, all log-transformed $\left[\log _{e}(\right.$ variable +1$\left.)\right]$. Region was included as a nominal variable. In order to know if the observed relationship between the explanatory variables and the different richness tested was the same in both regions, we performed slope homogeneity test considering all possible interaction terms between region and the six explanatory variables. A significant result in this interaction terms indicates that the relationship between the explanatory variable and richness is not the same in the two regions. Moreover, since the interaction between salinity and temperature was of interest due to a possible synergistic effect (Aladin and Potts 1995 and references therein), this interaction term was also included in all analyses. The Spearman correlation coefficients for the six continuous variables used in the GLMs were never higher than 0.4 . GLM calculations were carried out with Brodgar 2.5.2 software. We used a Poisson error distribution for the response variables (richness) and a logarithmic link function. The selected variables included in the final model were obtained using an automatic stepwise selection, and the Akaike information criterion (AIC) was used to select the best model with increasing complexity. However, automatic stepwise procedures are rather generous about leaving terms in the model. Therefore, the increase in deviance caused by each variable included in the model and obtained with the stepwise selection was tested, and only variables causing a significant change in deviance were retained in the final model. F-test was performed to obtain the significance of the variation explained by each selected variable, because it is less sensible to overdispersion problems (Crawley 2002).

\section{Trophic structure}

To explore food web relationships, we took a random subset of the above mentioned zooplankton samples (Denmark, $\mathrm{n}=34$; Catalonia, $\mathrm{n}=22$ ) and counted (at least 100 individuals of the most abundant taxa) rotifers, copepods

Table 2. Species richness per visit (mean and range), $\tau(\mathrm{h})$ (mean and $95 \% \mathrm{Cl}$ ), and Chao2 estimator (mean and $95 \% \mathrm{Cl}$ ) for each region and season. Note that $\tau(h)$ values are rarefied at a sample size of $n=15$ (the minimum sample size) for comparison purposes. The values correspond to total species richness, cladoceran, cyclopoid and calanoid richness.

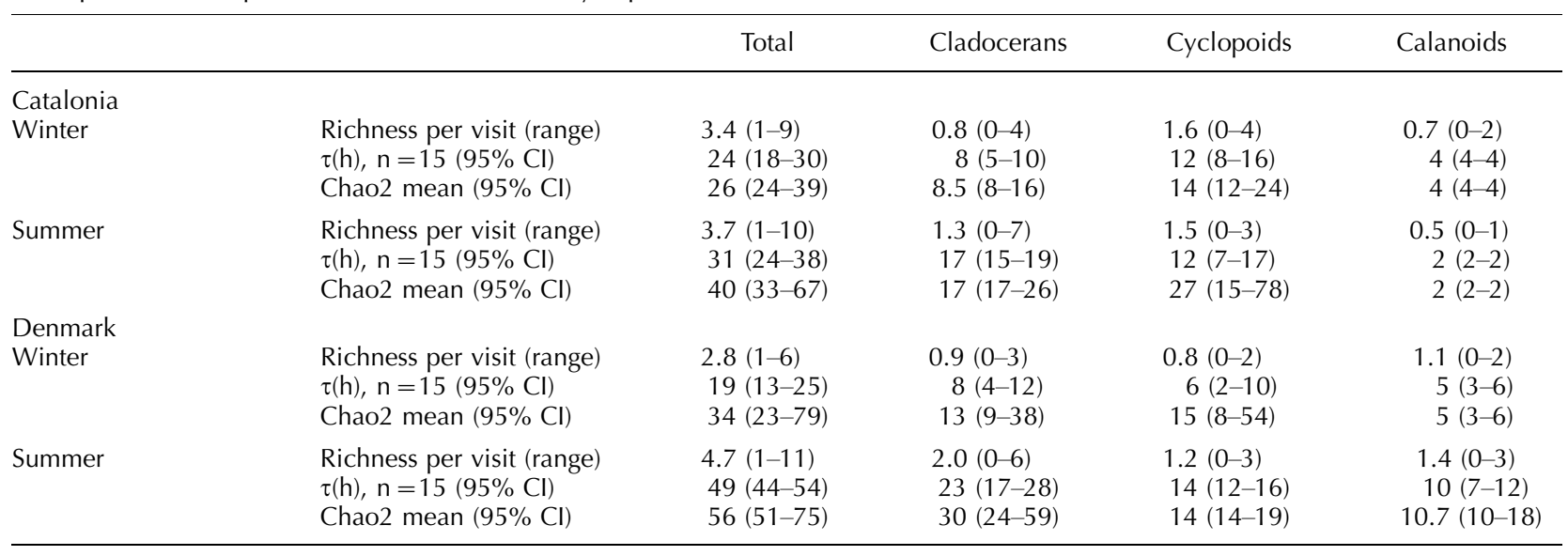


and cladocerans. Copepods and cladoceran dry weight estimations were obtained from the allometric relationship between the weight and the length of the body (Dumont et al. 1975, Bottrell et al. 1976, McCauley 1984, Malley et al. 1989). For rotifers, dry weight was estimated by converting biovolume into dry weight. Biovolume was obtained by approximation of the body shape to geometric figures (Ruttner-Kolisko 1977). For determination of the zooplankton:phytoplankton biomass ratio, chlorophyll-a was converted to phytoplankton dry weight (DW) using a chlorophyll-a:carbon(C)-ratio of 30 and a DW:C ratio of 2.2 (Jeppesen et al. 1994).

\section{Results}

\section{Species richness}

Total and cladoceran species richness per visit was significantly higher in summer (ANOVA, $\mathrm{p}<0.01$ and $\mathrm{p}<$ 0.05 , respectively) than in winter, but did not differ among regions (Table 2). Cyclopoid species richness per visit was higher in Catalonia than in Denmark (ANOVA, $p<0.01$ ) and no differences were found between seasons. Calanoid species richness per visit was higher in both seasons in Denmark (ANOVA, $\mathrm{p}<0.01$ ) than in Catalonia. In Denmark, calanoid richness was higher in summer, whereas in Catalonia it was higher in winter (ANOVA, interaction region $\times$ season $\mathrm{p}<0.05)$.

According to rarefaction curves and the $\tau(\mathrm{h})$ estimator, total species richness in Danish lagoons during summer was significantly higher than in winter and than in Catalan lagoons (Table 2, Fig. 1A). Based on the criterion for significant difference between Chao 2 estimators of no overlap among $95 \% \mathrm{CI}$, total species richness was similar in Denmark during summer and winter and not different from richness in Catalonia during summer (Table 2). According to rarefaction curves and the $\tau(\mathrm{h})$ estimator, cladoceran richness was significantly higher in summer than in winter in both regions (Table 2, Fig. 1B). However, following the Chao2 estimator, cladoceran richness did not differ between seasons in Denmark (Table 2). For cyclopoid richness, similar rarefaction curves and Chao 2 estimators were found in both places and in both seasons (Table 2, Fig. 1C). But according to the $\tau(\mathrm{h})$ estimator, cyclopoid richness in Denmark was significantly higher during summer than in winter. For calanoids, rarefaction curves, $\tau(\mathrm{h})$ and Chao2 estimators showed significantly higher values for Denmark during summer than in Catalonia (Table 2, Fig. 1D). Both estimators showed that calanoid richness in Denmark was higher in summer than in winter, while in Catalonia rarefaction curves and both estimators showed that calanoid richness was significantly higher in winter.

The zooplankton community in both regions contained elements from marine, estuarine and freshwater environments. Despite the relatively similar zooplankton species richness in Catalonia and Denmark, the Sørensen similarity index was low $(\mathrm{Q} S=0.26)$. The common species in both regions were euryhaline or species tolerant of intermediate salinity (Supplementary material Appendix 1, Fig. 2). Among the calanoids, the euryhaline Eurytemora velox was common in both regions. Other euryhaline calanoids were present only in one region; thus, Calanipeda aquaedulcis was only present in Catalonia, and Eurytemora affinis and Acartia tonsa only occurred in Denmark. The freshwater
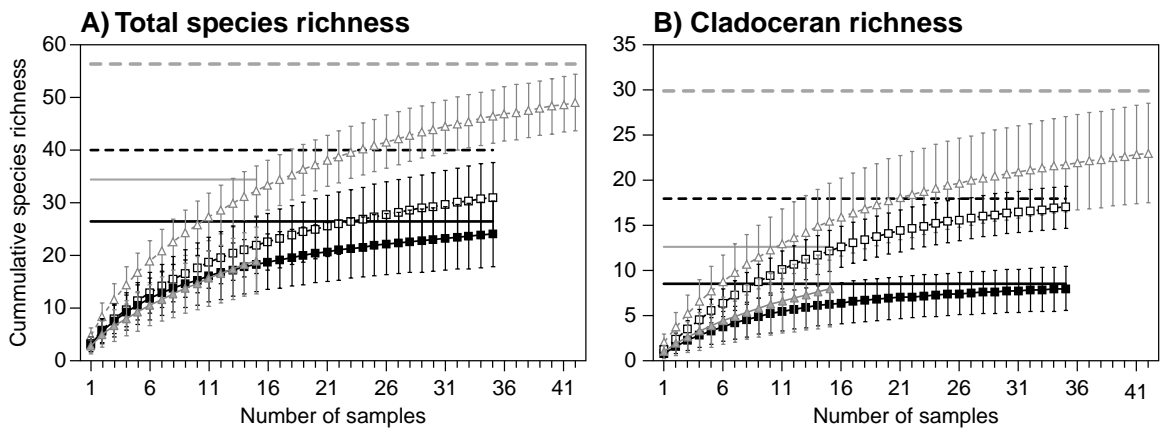

C) Cyclopoid richness

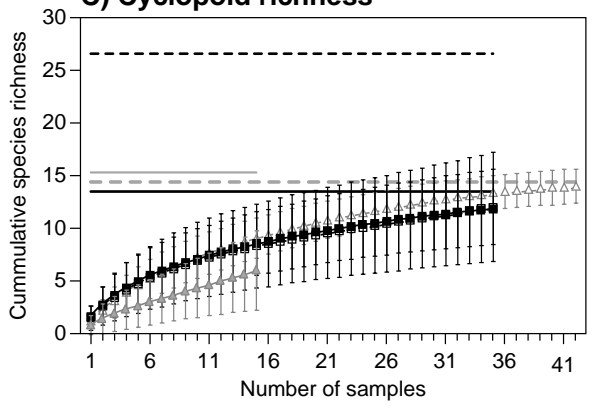

D) Calanoid richness

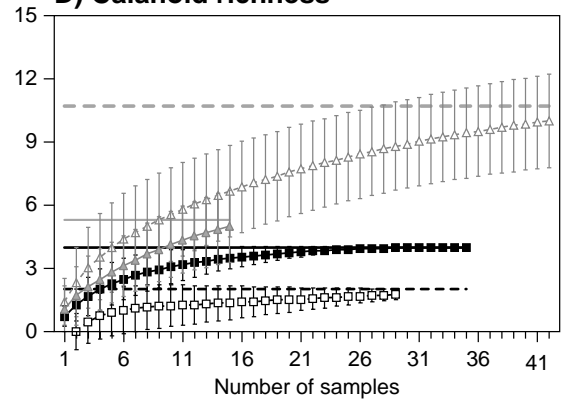

Catalonia:--Winter - - - Summer

Denmark: $₫-$ Winter $-\triangle$ - Summer

Figure 1. Sample-based rarefaction curves $(\tau(\mathrm{h})$ with $95 \% \mathrm{CI})$ and total species richness calculated using the Chao 2 estimator (a horizontal solid line for winter and a horizontal dashed line for summer) of total species richness (A), cladoceran richness (B), cyclopoid richness (C), and calanoid richness (D). Black: Catalan lagoons, grey: Danish lagoons. Filled symbols: winter, open symbols: summer. 


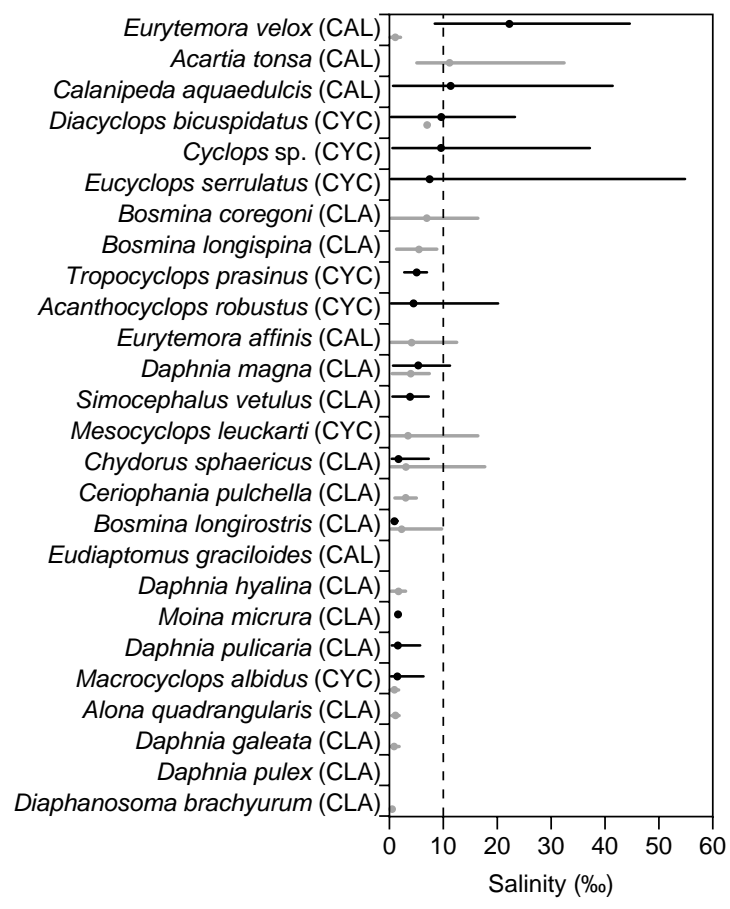

Figure 2. Means and ranges of salinity of the twenty six most abundant cladoceran (CLA), cyclopoid (CYC) and calanoid (CAL) species in Catalan (black) and Danish lagoons (grey).

calanoids Eudiaptomus gracilis and Eudiaptomus graciloides were absent in Catalonia, and Mixodiaptomus kupelwieseri was absent in Denmark. Among non-Chydoridae cladocerans, only the euryhaline Daphnia magna and Bosmina longirostris, tolerant of intermediate salinities (Flössner 1972), and the oligohaline Ceriodaphnia dubia were common in both regions. Among Chydoridae, the euryhaline Chydorus sphaericus and the oligohaline Alona affinis were present in both regions. The composition of cyclopoid species was also different. Only three cyclopoids were common in both regions. Diacyclops bicuspidatus and Megacyclops viridis, both of which can tolerate moderate (Dussart 1969) to high salinities (this study), and Macrocylops albidus, more typical of freshwater, were also common in both regions.

\section{Effects of environmental variables on community structure}

From the GLM analyses run for each season, only salinity and region were selected in more than one model (Table 3, Fig. 3). Salinity had a linear negative effect on total, cladoceran and cyclopoid richness in both seasons. TP was incorporated only in the model for cladoceran richness in winter and had a linear positive response. Although in both regions similar slopes were observed for the models of total and cyclopoid richness in winter, the intercept of the model was significantly lower for Denmark $(p<0.01)$. No variables were selected for calanoid richness. It is noteworthy that the interaction between region and salinity is not significant in any group, implying that the negative influence of salinity was similar in both regions (Fig. 4). Even though the salinity range of the Danish lagoons in winter was smaller
Table 3. Significance level (p), degrees of freedom of the smoother (DF), and variance explained for the variables incorporated in the generalized linear model. Results obtained for total, cladoceran, and cyclopoid taxonomic richness are shown. Each analysis was performed separately for the winter and summer samplings. No variable was selected for calanoid taxonomic richness.

\begin{tabular}{lrccc}
\hline Explanatory variable & F-values & $p$ & DF & $\begin{array}{c}\text { Variance } \\
\text { explained }\end{array}$ \\
\hline $\begin{array}{l}\text { Winter } \\
\quad \text { Total richness }\end{array}$ & & & & \\
$\quad$ Region & & & & $43.3 \%$ \\
$\quad$ Salinity & 18.93 & $<0.01$ & 1 & \\
$\quad$ Cladoceran richness & & $<0.001$ & 1 & \\
$\quad$ Salinity & 23.86 & $<0.001$ & 1 & $34.8 \%$ \\
$\quad$ TP & 4.95 & 0.05 & 1 & \\
$\quad \begin{array}{l}\text { Cyclopoid richness } \\
\quad \text { Region }\end{array}$ & 13.06 & $<0.01$ & 1 & \\
$\quad$ Salinity & 10.17 & $<0.001$ & 1 & \\
$\begin{array}{l}\text { Summer } \\
\quad \text { Total richness }\end{array}$ & & & & \\
$\quad$ Salinity & 39.09 & $<0.001$ & 1 & $35.6 \%$ \\
$\quad \begin{array}{l}\text { Cladoceran richness } \\
\quad \text { Salinity }\end{array}$ & 58.11 & $<0.001$ & 1 & $38.0 \%$ \\
$\quad$ Cyclopoid richness & & & & $7.8 \%$ \\
$\quad$ Salinity & 5.50 & $<0.05$ & 1 & \\
\hline
\end{tabular}

than in summer, the negative relationship between salinity and richness was similar in both seasons (Fig. 4).

Calanoids and cyclopoids had the highest salinity tolerances in both countries (Fig. 2). Whereas in Catalonia several euryhaline species were found at salinities $>20 \%$ (e.g. Eurytemora velox, Calanipeda aquaedulcis, Diacyclops bicuspidatus, Eucyclops serrulatus), in Denmark only Acartia tonsa appeared at these salinities. In Catalonia, the number of cyclopoid species adapted to high salinities was also higher than in Denmark (4 cyclopoid species at salinities $>10 \%$ in Catalonia versus 1 in Denmark). Cladocerans were restricted to lower salinities in both countries. Only Chydorus sphaericus and Bosmina coregoni in Denmark and Daphnia magna in Catalonia appeared at salinities $>10 \%$. The remaining Daphnia species were found only at low salinity $(<10 \%)$ and, with the exception of $D$. pulicaria, all had very low salinity tolerances. At salinities $>18 \%$ cladocerans disappeared. In both regions, the ratio of large cladoceran:total zooplankton in terms of abundance decreased at increasing salinity (Fig. 5). Large cladocerans were present at salinities $>10 \%$ in only a few lagoons.

\section{Trophic structure}

Although water level data for the Danish brackish lagoons were not available, major changes between winter and summer were not common due to the temperate climate. In contrast, in Catalonia the water level in the lagoons during summer was significantly lower than in winter (ANOVA, $p<0.001)$ and increases from 20 up to $70 \%$ in the water level were recorded from summer to winter. No significant differences in salinity were found between the two regions even though maximum values were higher in Catalonia in both seasons (Fig. 6). Chlorophyll-a, chlorophyll-a:TP and chlorophyll-a:TN ratios did not differ significantly between the countries in summer, but were higher in Denmark in winter (ANOVA, $\mathrm{p}<0.001$; Fig. 6). 

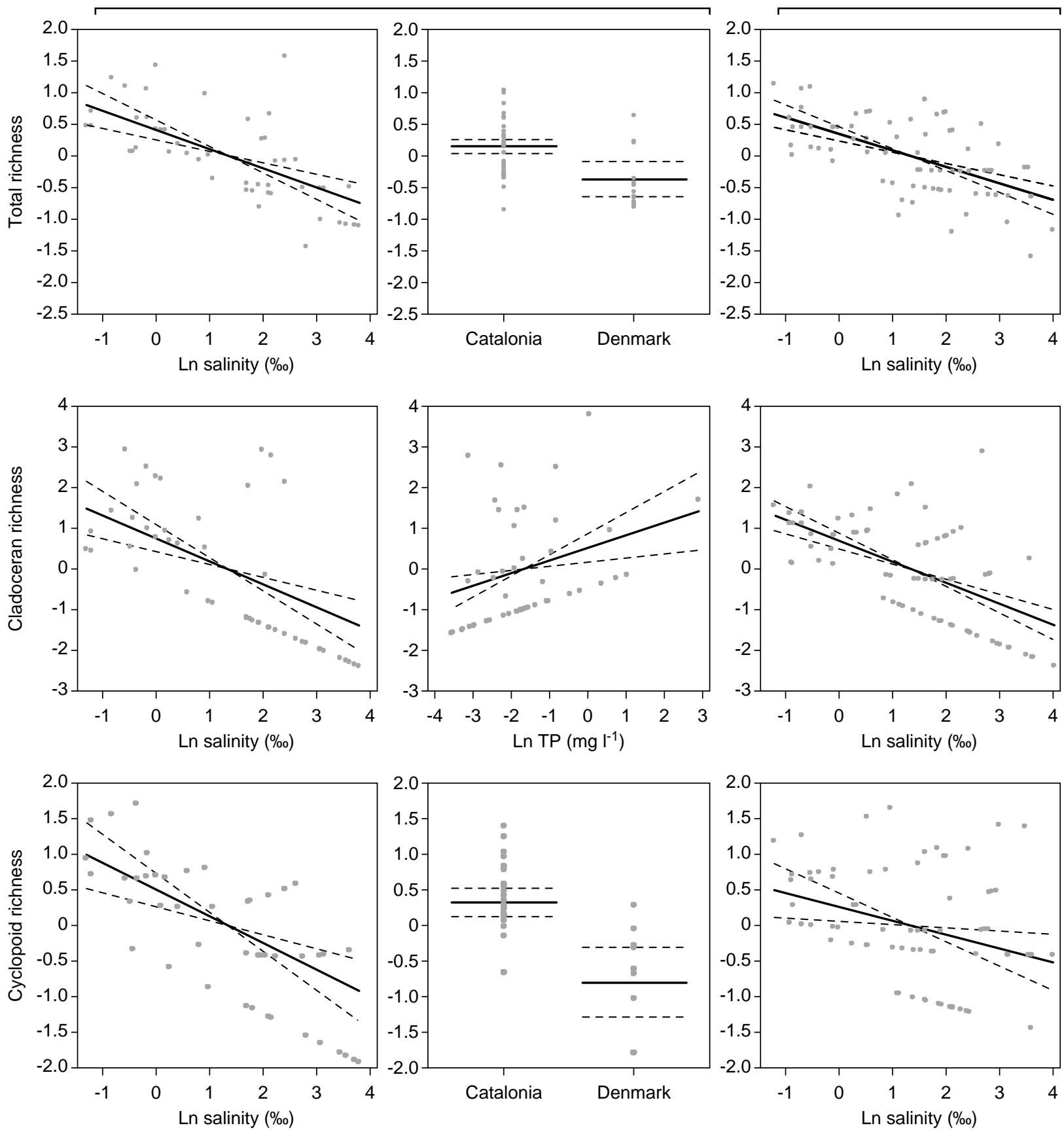

Figure 3. Partial plots for total, cladoceran and cyclopoid species richness and the variables incorporated in the generalized linear model. Box plots of the residuals of factor region are also shown. Winter and summer samplings on the left and right, respectively. Dashed lines are approximate $95 \%$ confidence intervals.

The lower winter values of chlorophyll-a, chlorophylla:TP and chlorophyll-a:TN ratios in Catalonia coincided with a significantly (ANOVA, $\mathrm{p}<0.001$ ) higher zooplankton:phytoplankton biomass ratios and thus potentially a higher zooplankton grazing on phytoplankton (Fig. 6). In winter, copepods contributed most importantly to the zooplankton biomass in Catalonia, while in Denmark copepods and rotifers were equally important (Fig. 7). In summer, a shift occurred in the zooplankton community in both regions: rotifer biomass increased in the Catalan lagoons and copepods in the Danish lagoons. In Catalonia this increase was followed by a decrease in the zooplankton:phytoplankton biomass ratio to a level similar to that in Denmark (ANOVA, $\mathrm{p}>0.05$; Fig. 6). The low contribution of cladocerans to zooplankton biomass in both regions is noteworthy (Fig. 7).

\section{Discussion}

Species richness of crustacean zooplankton in brackish temperate lagoons in Denmark and Mediterranean lagoons 

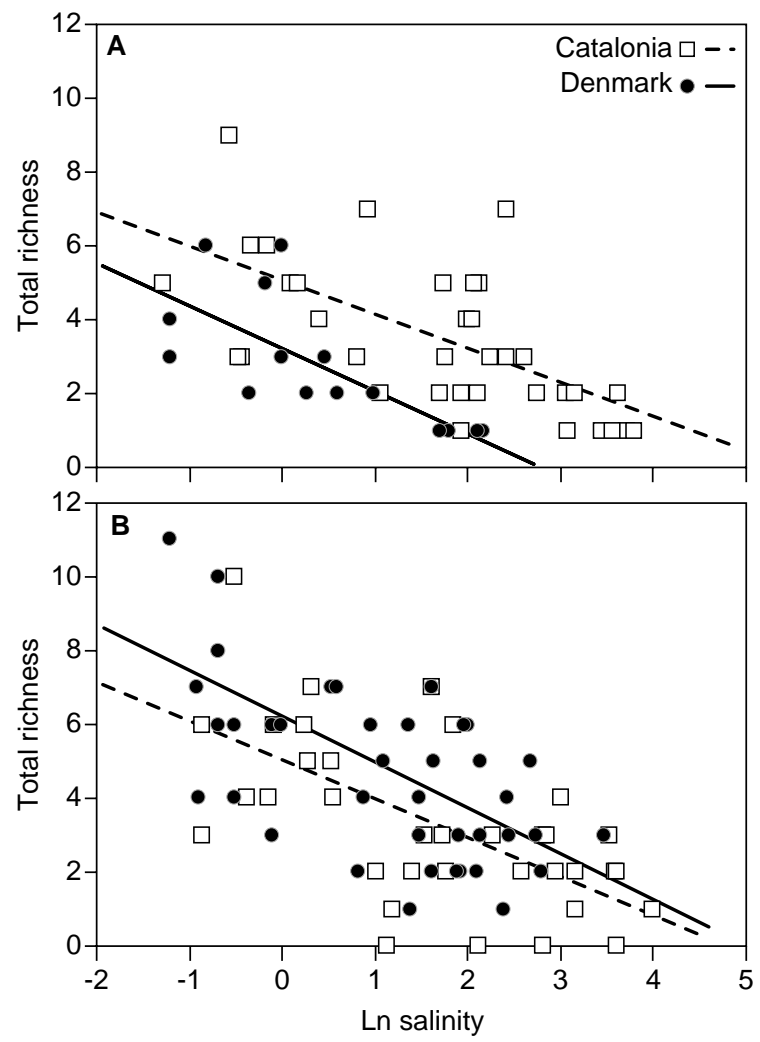

Figure 4. Relationship between total species richness and salinity in Catalan and Danish lagoons in winter (A) and summer (B).

in Catalonia was similar and, in accordance with previous studies (Jeppesen et al. 1994, Moss 1994), it was overall lower than in comparable freshwater lakes. The only differences among regions were found during summer when higher calanoid richness was recorded in Denmark. As opposed to freshwater lakes (Pinto-Coelho et al. 2005 and references therein), cladoceran species richness in brackish lakes was similar in the two climatic regions, likely reflecting that salinity is the key controlling factor. In spite of the differences in species composition between Denmark and Catalonia, increasing salinity overall had a negative effect on total richness as well as on cladoceran and cyclopoid species richness in both regions, which is in accordance with previous findings in other temperate (Jeppesen et al. 1994), Mediterranean (Boronat et al. 2001) and tropical (Attayde and Bozelli 1998) brackish lagoons. The higher calanoid richness and slightly lower cyclopoid richness in Denmark contrast with the results of Meerhoff et al. (2007) who suggested lower calanoid richness and higher cyclopoid richness in temperate freshwater lakes than in tropical freshwater lakes.

As previously reported for temperate brackish lagoons (Heerkloss et al. 1991, Jeppesen et al. 1994), a shift occurred in both regions from dominance at low salinities of large cladoceran species with a broad-sized feeding spectrum to dominance at higher salinities of copepods (mainly calanoids) and small cladoceran species, such as Bosmina and Chydorus, which feed on a more narrow-sized food spectrum. Typically, the important phytoplankton grazer Daphnia disappears at salinities $>2 \%$ o (Jeppesen et al. 1994), with the exception of Daphnia magna which
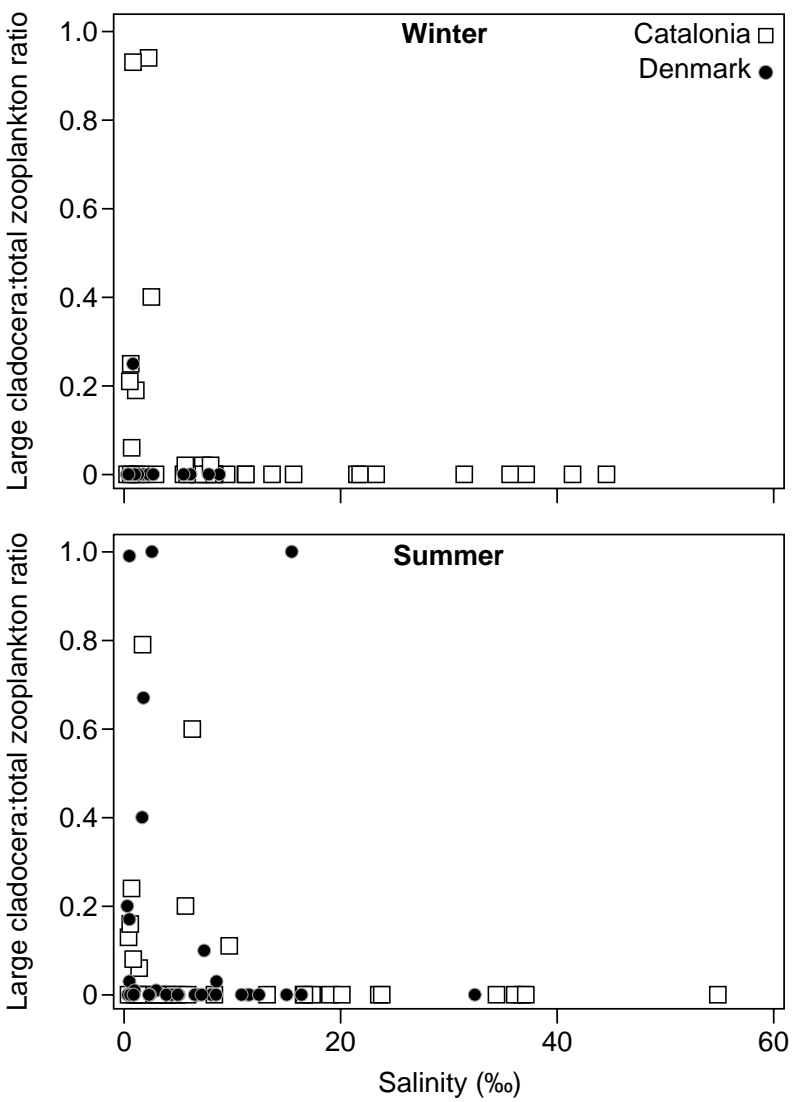

Figure 5. Relationship between salinity and the large cladocerans: total zooplankton ratio in terms of abundance found in Catalan and Danish brackish lagoons for winter and summer samples.

tolerates salinities up to $8 \%$ (Arnér and Koivisto 1993). In Catalonia, three large cladocerans, D. magna, Daphnia pulicaria and Simocephalus vetulus, were present at salinities $>5 \%$, while only D. magna was present at these salinities in Denmark. The salinity tolerances of $D$. magna found in Catalan lagoons are higher than the previously reported $8 \%$ in temperate lakes, but similar to the ones reported for other Mediterranean lakes (Boronat et al. 2001, Green et al. 2005). As observed for cladocerans, we recorded more copepod species at high salinities in the Mediterranean than in the temperate region. Temperature differences could explain the different salinity tolerance between regions since osmoregulatory ability of some species depends on temperature (Aladin and Potts 1995 and references therein). However, the effects of temperature on osmoregulation are complex (Aladin and Potts 1995) and vary among species. While for some cladoceran species osmoregulatory ability increases with temperature (e.g. Daphnia magna, Moina macrocopa; Aladin and Potts 1995), higher salinity tolerance at lower temperature has been reported for some copepods (e.g. Boeckella hamata, Eurytemora velox, Sulcanus conflictus; Hall and Burns 2002 and references therein). Cladocerans also exhibit different physiological tolerances to different ionic components, the upper tolerance of a species depending mainly on the chloride concentration (Aladin 1991). Since the salinity of athalassic lakes is characterised by a more heterogeneous ionic composition than coastal brackish lagoons (Aladin and Potts 1995), some Daphnia species have been found in these lakes 

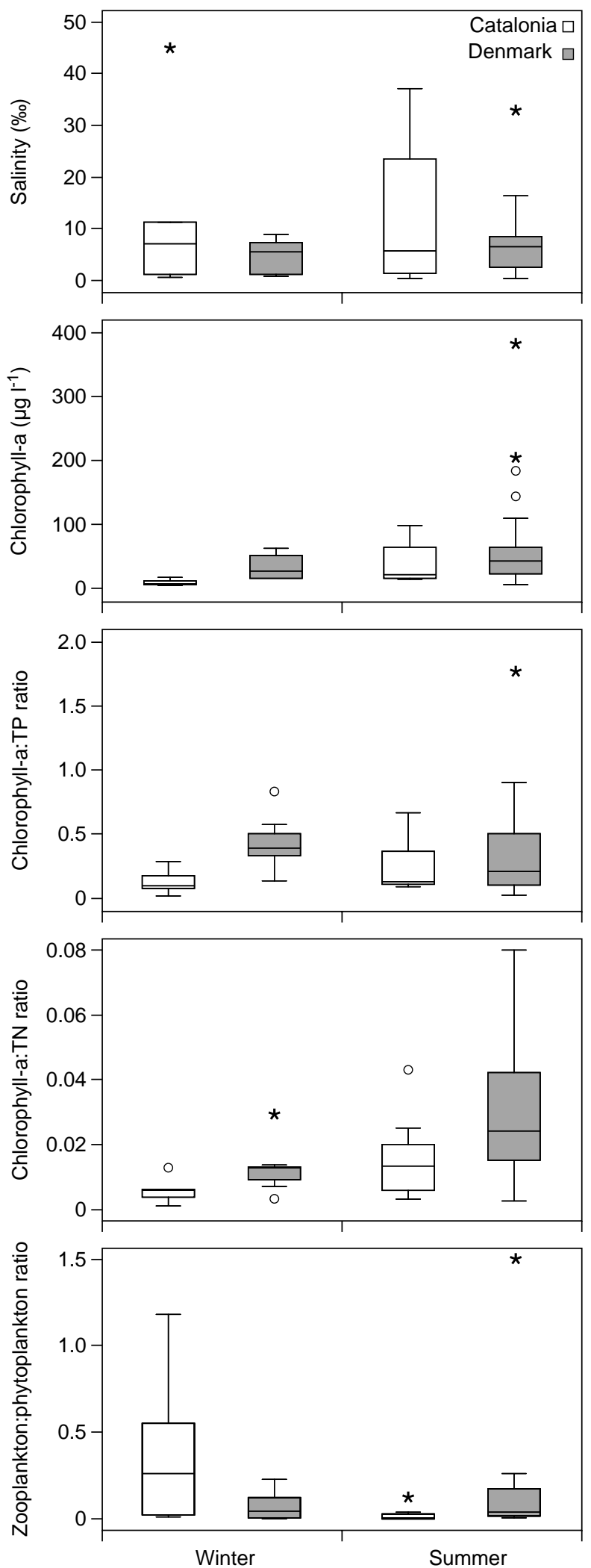

Figure 6. Winter and summer values in Catalonia (white) and Denmark (grey) of salinity $(\%)$, chlorophyll-a $\left(\mu \mathrm{gl}^{-1}\right)$, the chlorophyll-a:TP ratio, the chlorophyll-a:TN ratio and the ratio of zooplankton to phytoplankton in terms of biomass. Mild outliers are represented by an open $\operatorname{dot}(>1.5 \times \mathrm{IQR}$ and $<3 \times$ IQR), and extreme outliers are represented by an asterisk $(>3 \times$ IQR). IQR, interquartile range.

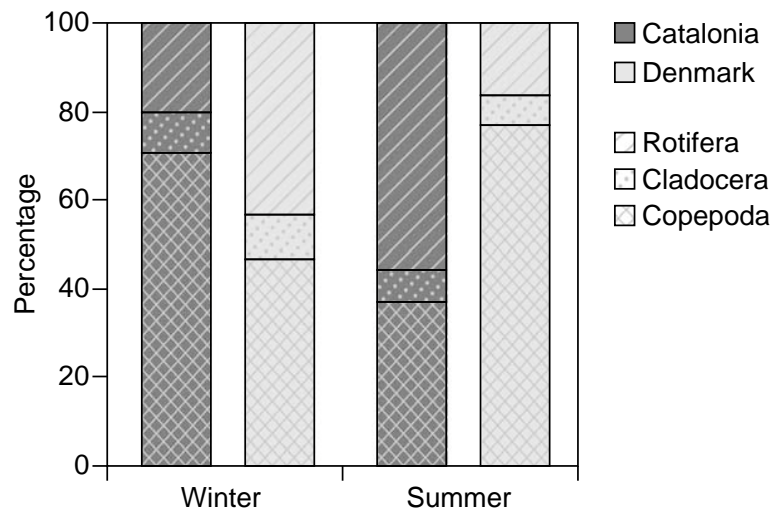

Figure 7. Percentage of biomass of each zooplankton group (rotifers, cladocerans, copepods) in winter and summer in Catalan and Danish brackish lagoons.

at salinities $>20 \%$ (Aladin and Potts 1995, Evans et al. 1996).

In contrast to cladoceran and cyclopoid richness, calanoid richness was not affected by salinity, or trophic state variables, in any region, although increased calanoid richness in oligotrophic freshwater lakes has previously been reported both at temperate and tropical latitudes (PintoCoelho et al. 2005). The lack of a relationship between calanoid richness and environmental variables may be due to the low number of calanoid species, preventing a clear significant relationship with the GLM model method. In Catalonia, higher richness of calanoids in freshwater lakes than in brackish lagoons has previously been found (Boix et al. 2008). In fact, 16 of the 24 calanoid species known in the Iberian Peninsula occur in freshwaters (Alonso 1998).

Trophic state variables were only significant for cladoceran richness, but were selected together with salinity. The increase in cladoceran richness with increasing TP contrasts with the general tendency to reduced zooplankton richness with elevated TP in both northern and southern lakes (Jeppesen et al. 2000, Declerck et al. 2005, Pinto-Coelho et al. 2005) and with the unimodal relationship between cladoceran richness and total phosphorus described for Danish freshwater lakes (Jeppesen et al. 2000, Declerck et al. 2005).

Major differences were found in trophic structure between the two climatic regions. In Denmark, the zooplankton:phytoplankton biomass ratio remained low during both seasons, whereas, in Catalonia, the ratio was remarkably higher in winter than in summer, which may be associated with a shift from copepod to rotifer dominance. The dominance of copepods coincides with the more stable environmental conditions in winter in Mediterranean lakes (Quintana et al. 1998, Ortega-Mayagoitia et al. 2000, Brucet et al. 2005, 2006). Changes in fish predation are a likely explanation of the pronounced changes in zooplankton structure from winter to summer in Catalan lagoons. During spring and early summer, the density of the dominant mosquitofish Gambusia holbrooki and Iberian toothcarp Aphanius iberus in these Catalan lagoons (Alcaraz and García-Berthou 2007a, b) increases following recruitment, leading to intense feeding on zooplankton (García-Berthou 1999, Mieiro et al. 2001, Alcaraz and García-Berthou 2007b). In Danish brackish lagoons, fish 
predation on zooplankton is often high throughout the year, which results in low zooplankton:phytoplankton biomass ratios (Jeppesen et al. 1997) and dominance of small sized zooplankton, such as copepods and rotifers, which are less efficient at controlling phytoplankton (Jeppesen et al. 1994, Jakobsen et al. 2003). The higher zooplankton:phytoplankton biomass ratios in the Catalan lagoons in winter relative to summer and to Danish lagoons are indicative of a higher grazing pressure on phytoplankton (Jeppesen et al. 2007a) and would explain the low chlorophyll-a, chla:TP and chla:TN ratios in Catalan lagoons in winter.

\section{Implications under a climate change scenario}

Differences in temperature between north temperate and Mediterranean brackish lagoons had no clear direct effects on zooplankton species richness; however, in both regions, zooplankton species richness was strongly negatively influenced by salinity. Trophic state variables had a comparatively minor influence. In a global warming perspective, our results suggest that the indirect effects of temperature changes on aquatic communities, such as changes in salinity and hydrology, could be more important than the direct effects of warming. Predicted higher temperatures will result in higher evaporation and higher demand for freshwater to for instance irrigation, and higher salinities can be expected in the Mediterranean zone, resulting in changes in species composition and a decrease in species richness. Some brackish and saline lagoons might be capable of coping with slight increases in salinity since the organisms dominating these systems can tolerate varying salinities, and well structured communities can be found at high salinities (Cognetti and Maltagliati 2000). However, rising salinity levels can be dramatic for slightly brackish waters $(<5 \%)$, whose communities comprise species from saline and freshwaters, and even worse for freshwater lakes (Schallenberg et al. 2003, Jeppesen et al. 2007a). The substantial changes in biodiversity due to desiccation and salinisation occurring in inland lakes like the Aral Sea and Australian lakes are well-known (Aladin 1991, Williams 2001). The shift in trophic structure (from dominance of large and more efficient filter-feeding cladocerans to dominance of copepods and small bodied cladocerans) occurring at increasing salinity will also lead to reduced grazing pressure on phytoplankton and a higher risk of a shift from a clear to a turbid state of brackish lagoons. Lower critical loadings of nutrients for shift from a clear to a turbid state can therefore be expected in the Mediterranean zone in a future warmer climate. Our findings also show more pronounced seasonal variation in trophic structure in the lagoons in the Mediterranean zone than in Denmark.

From a management perspective, the strong influence of salinity in brackish lagoons also implies that knowledge gained from freshwater lakes about species richness patterns and food web structure cannot readily be extrapolated to brackish lagoons. More studies of brackish lagoons are needed to improve our knowledge of the functioning of these valuable ecosystems that may increase in number as a result of global warming.

Acknowledgements - This work was supported by a grant from the Comisión de Investigación Científica y Técnica (CICYT), Programa Nacional de Biodiversidad, Ciencias de la Tierra y Cambio Global (ref. CGL2004-05433/BOS) and in Denmark by the EU FP6 project Eurolimpacs, CLEAR (a Villum Kann Rasmussen Centre of Excellence project), Galathea 3 and the Research Council for Nature and Universe (272-08-0406). S.B. held a postdoctoral Beatriu Pinós grant from the Dept d'Universitats, Recerca i Societat de la Informació de la Generalitat de Catalunya. We sincerely thank A. M. Poulsen for editorial assistance, T. Christensen for graphical assistance and three anonymous reviewers whose comments improved the manuscript.

\section{References}

Aladin, N. V. 1991. Salinity tolerance and morphology of the osmoregulation organs in Cladocera with special reference to Cladocera from the Aral Sea. - Hydrobiologia 225: 291-299.

Aladin, N. V. and Potts, W. T. W. 1995. Osmoregulatory capacity of the Cladocera. - J. Comp. Physiol. B 164: 671-683.

Alcaraz, C. and García-Berthou, E. 2007a. Life history variation of invasive mosquito fish (Gambusia holbrooki) along a salinity gradient. - Biol. Conserv. 139: 83-92.

Alcaraz, C. and García-Berthou, E. 2007b. Food of an endangered cyprinodont (Aphanius iberus): ontogenetic diet shift and prey electivity. - Environ. Biol. Fish. 78: 193-207.

Alonso, M. 1998. Las lagunas de la España peninsular. - Limnetica 15: 1-176.

APHA 1989. Standard methods for the examination of water and wastewater, 17th ed. - American Public Health Association, Washington, DC.

Arnér, M. and Koivisto, S. 1993. Effects of salinity on metabolism and life history characteristics of Daphnia magna. - Hydrobiologia 259: 69-77.

Attayde, J. L. and Bozelli, R. L. 1998. Assessing the indicator properties of zooplankton assemblages to disturbance gradients by canonical correspondence analysis. - Can. J. Fish. Aquat. Sci. 55: 1789-1797.

Badosa, A. et al. 2007. Zooplankton taxonomic and size diversity in Mediterranean coastal lagoons (NE Iberian Peninsula): influence of hydrology, nutrient composition, food resource availability and predation. - Estuar. Coast. Shelf Sci. 71: 335346.

Beklioglu, M. et al. 2007. State of the art in the functioning of shallow Mediterranean lakes: workshop conclusions. - Hydrobiologia 584: 317-326.

Blanco, S. et al. 2003. Fish communities and food web interactions in some shallow Mediterranean lakes. - Hydrobiologia 506/509: 473-480.

Boix, D. et al. 2008. Patterns of composition and species richness of crustaceans and aquatic insects along environmental gradients in Mediterranean water bodies. - Hydrobiologia 597: 53-69.

Boronat, L. et al. 2001. Cladoceran assemblages in a mineralization gradient. - Hydrobiologia 442: 5-88.

Bottrell, H. H. et al. 1976. A review of some problems in zooplankton production studies. - Norw. J. Zool. 24: 419-456.

Brucet, S. et al. 2005. Zooplankton structure and dynamics in permanent and temporary Mediterranean salt marshes: taxonbased and size-based approaches. - Archiv Hydrobiol. 162: 535-555. 
Brucet, S. et al. 2006. Size and species diversity of zooplankton communities in fluctuating Mediterranean salt marshes. - Estuar. Coast. Shelf Sci. 67: 424-432.

Cognetti, G. and Maltagliati, F. 2000. Biodiversity and adaptive mechanisms in brackish water fauna. - Mar. Pollut. Bull. 40: $7-14$.

Colwell, R. K. 2005. EstimateS: statistical estimation of species richness and shared species from samples. Version 7.5. - User's guide and application published at <http://purl.oclc.org/ estimate $>$.

Colwell, R. K. et al. 2004. Interpolating, extrapolating, and comparing incidence-based species accumulation curves. - Ecology 85: 2717-2727.

Cottenie, K. et al. 2003. Zooplankton metacommunity structure: regional vs local processes in highly interconnected ponds. - Ecology 84: 991-1000.

Crawley, M. J. 2002. Statistical computing. An introduction to data analysis using S-Plus. - Wiley.

Declerck, S. et al. 2005. Multi-group biodiversity in shallow lakes along gradients of phosphorus and water plant cover. - Ecology 86: 1905-1915.

Dumont, H. J. et al. 1975. The dry weight estimate of biomass in a selection of Cladocera, Copepoda and Rotifera from plankton, periphyton and benthos of continental waters. - Oecologia 19: 75-97.

Dussart, B. 1969. Les Copépodes des Eaux Continentales, Vol. II. - Éditions N. Boubeé, Paris.

Evans, M. S. et al. 1996. Algal productivity, algal biomass, and zooplankton biomass in a phosphorus-rich, saline lake: deviations from regression model predictions. - Can. J. Fish. Aquat. Sci. 53: 1048-1060.

Flössner, D. 1972. Krebstiere, Crustacea. Kiemen- und Blattfüsser, Branchiopoda; Fischläuse, Branchiura. - Tierwelt Deutschlands 60: 1-501.

García-Berthou, E. 1999. Food of introduced mosquito fish: ontogenetic diet shift and prey selection. - J. Fish. Biol. 55: 135-147.

Grasshoff, K. et al. 1983. Methods of seawater analysis. - Verlag Chemie, Weinheim.

Green, A. J. et al. 2005. Factors influencing cladoceran abundance and species richness in brackish lakes in eastern Spain. - Ann. Limnol. Int. J. Lim. 41: 73-81.

Grindley, J. R. 1981. Estuarine plankton. - In: Day, J. H. (ed.), Estuarine ecology with particular reference to southern Africa. A. A. Balkema, Cape Town, pp. 117-146.

Gyllström, M. et al. 2005. The role of climate in shaping zooplankton communities of shallow lakes. - Limnol. Oceanogr. 50: 2008-2021.

Hall, C. J. and Burns, C. W. 2002. Effects of temperature and salinity on the survival and egg production of Gladioferens pectinatus Brady (Copepoda: Calanoida). - Estuar. Coast. Shelf Sci. 55: 557-564.

Heerkloss, R. et al. 1991. Seasonal variation in the biomass of zooplankton in two shallow coastal water inlets differing in their stage of eutrophication. - Int. Rev. Ges. Hydrobiol. 76: $397-404$.

Hortal, J. et al. 2006. Evaluating the performance of species richness estimators: sensitivity to sample grain size. - J. Anim. Ecol. 75: 274-287.

Irvine, K. et al. 1990. Tropic relations in Hickling Broad - a shallow and brackish eutrophic lakes. - Verh. Int. Verei. Limnol. 24: 576-579.

Jakobsen, T. S. et al. 2003. Impact of three-spined stickleback Gasterosteus aculeatus on zooplankton and chl a in shallow, eutrophic, brackish lakes. - Mar. Ecol. Prog. Ser. 262: 277284.
Jeppesen, E. et al. 1994. Does the impact of nutrients on the biological structure and function of brackish and freshwater lakes differ? - Hydrobiologia 275/276: 15-30.

Jeppesen, E. et al. 1997. Macrophytes and turbidity in brackish lakes with special emphasis on top-down control. - In: Jeppesen, E. et al. (eds), The structuring role of submerged macrophytes in lakes. Springer, pp. 369-377.

Jeppesen, E. et al. 2000. Trophic structure, species richness and biodiversity in Danish lakes: changes along a phosphorus gradient. - Freshwater Biol. 45: 201-218.

Jeppesen, E. et al. 2007a. Salinity induced regime shift in shallow brackish lagoons. - Ecosystems 10: 47-57.

Jeppesen, E. et al. 2007b. Restoration of shallow lakes by nutrient control and biomanipulation - the successful strategy depends on lake size and climate. - Hydrobiologia 581: 269-288.

Koroleff, F. 1970. Determination of total phosphorus in natural water by means of persulphate oxidation. - Interlaboratory report no. 3, Conserv. Int. Pour l'Explor. de la Mer.

Lazzaro, X. et al. 2003. Do fish regulate phytoplankton in shallow northeast Brazilian reservoirs? - Freshwater Biol. 48: 649-668.

Malley, D. F. et al. 1989. Range of variation in estimates of dry weight for planktonic Crustacea and Rotiera from temperate north American lakes. - Can. Tech. Rep. Hydrogr. Fish. Aquat. Sci. 1666: 1-49.

McCauley, F. E. R. 1984. The estimation of the abundance and biomass of zooplankton in samples. - In: Downing, J. A. and Rigler, F. H. (eds), A manual on the assessment of secondary productivity in fresh waters. Blackwell, pp. 228-265.

McCullagh, P. and Nelder, J. A. 1989. Generalized linear models. - Chapman and Hall/CRC.

Meerhoff, M. et al. 2007. Effects of habitat complexity on community structure and predator avoidance behaviour of littoral zooplankton in temperate versus subtropical shallow lakes. - Freshwater Biol. 52: 1009-1021.

Mieiro, C. L. et al. 2001. Predation pressure of introduced mosquitofish (Gambusia holbrooki Girard), on the native zooplankton community. A case-study from representative habitats in the lower Mondego river Valley (Portugal). - Limnetica 20: 279-292.

Moss, B. 1994. Brackish and freshwater shallow lakes - different systems or variations on the same theme? - Hydrobiologia 275/276: 1-14.

Oertli, B. et al. 2002. Does size matter? The relationship between pond area and biodiversity. - Biol. Conserv. 104: 59-70.

Ortega-Mayagoitia, E. et al. 2000. Structure and dynamics of zooplankton in a semi-arid wetland, the National Park Las Tablas de Daimiel (Spain). - Wetlands 20: 629-638.

Pinto-Coelho, R. et al. 2005. Crustacean zooplankton in lakes and reservoirs of temperate and tropical regions: variation with trophic status. - Can. J. Fish. Aquat. Sci. 62: 348-361.

Quintana, X. D. et al. 1998. Nutrient and plankton dynamics in a Mediterranean salt marsh dominated by incidents of flooding. Part. 2: response of the zooplankton community to disturbances. - J. Plankton Res. 20: 2109-2127.

Romo, S. et al. 2004. Mesocosm experiments on nutrient and fish effects on shallow lake food webs in a Mediterranean climate. - Freshwater Biol. 49: 1593-1607.

Ruttner-Kolisko, A. 1977. Suggestions for biomass calculations of plankton rotifers. - Arch. Hydrobiol. Beih. Ergebn. Limnol. 8: 71-76.

Schallenberg, M. et al. 2003. Consequences of climate-induced salinity increases on zooplankton abundance and diversity in coastal lakes. - Mar. Ecol. Prog. Ser. 251: 181-189.

Solórzano, L. and Sharp, J. H. 1980. Determination of total dissolved nitrogen in natural waters. - Limnol. Oceanogr. 25: 751-754. 
Talling, J. F. and Driver, D. 1963. Some problems in the estimation of chlorophyll a in phytoplankton. - In: Doty, M. (ed.), Primary productivity measurements, marine and freshwater. Univ. of Hawaii, 1961, US Atomic Energy Communication, TID-7633, pp. 142-146.

Download the Supplementary material as file E5823 from $<$ www.oikos.ekol.lu.se/appendix $>$.
Williams, W. D. 2001. Anthropogenic salinisation of inland waters. - Hydrobiologia 466: 329-337.

Williams, W. D. et al. 1990. Salinity as a determinant of salt lake fauna: a question of scale. - Hydrobiologia 197: 257-266. 